\title{
Vuca Dönemlerinde Coso Kurumsal Risk Yönetiminin Önemi: Covid-19 Salgın Sonrası Yükseköğretim Kurumları İçin Model Önerisi
}

DOI: 10.26466/opus.791495

*

\section{Gencay Karakaya *}

\author{
* Dr. Öğretim Üyesi, İstanbul Ticaret Üniversitesi, İşletme Fakültesi, İstanbul \\ E-Posta: gkarakaya@ticaret.edu.tr \\ ORCID: 0000-0002-2662-6031

\section{Öz}

Kurumlarm katma değer oluşturacak şekilde yönetilmeleri için birden fazla yönetim modeli ve teorisi geliştirilmiştir. 2000'li yılların başına kadar çoğunlukla özel sektör işletmelerinde görülen bu uygulamalar, bu tarihten itibaren ayrım gözetmeksizin tüm idarelerin dikkatini çekmiş ve uygulanmıştır. Bu noktada kurumsal risk yönetiminin (KRY) teori ve uygulamaları, gerek özel sektör kuruluşlarının gerek kamu idarelerinin programlarında yer almaya başlamıştır. Belirsizlikleri azami ölçüde ortadan kaldırma, değişimlere olan duyarlılı̆̆ı artırma ve olası karmaşıklı̆̆ önlemeyi amaçlayan KRY; son dönemlerde önemi giderek artan başka bir kavram ile teori bazında örtüşmektedir. Bu kavram VUCA kavramıdır. İş dünyası başta olmak üzere tüm alanlarda konuşulmaya başlanan VUCA; volatility (değişkenlik), uncertainty (belirsizlik), complexity (karmaşıklı) ve ambiguity (muğlaklık) kelimelerinin baş harflerinden oluşmaktadır. KRY modelinin temelinde önlemeyi amaçladiğı her sorun, VUCA dönemlerinde idarelerin önüne çımaktadır. Bu anlamda önemi ve görevi giderek artan yükseköğretim kurumları, bir VUCA dönemi olarak COVID-19 salgin süreci ve sonrasinda etkin ve verimli bir $K R Y^{\prime} n e$ ihtiyaç duymaktadır. Ülkemizde yükseköğretim kurumları KRY rehberleri düzenlemekte ve kamuoyu ile paylaşmaktadır. Ancak 2020 yılı itibariyle gündemimize giren ve daha ne kadar gündemimizde kalacağın bilmediğimiz COVID-19 salgını, yükseköğretim kurumlarında bundan sonrası için, modern, güncel ve ihtiyaca uygun bir KRY rehberini elzem hale getirmiştir. Çalışma kapsamında salgın sonrası, yükseköğretim kurumlarının etkin KRY süreçlerini işletebilmeleri adına bir model önerisinde bulunulmuştur.

Anahtar Kelimeler: Kurumsal Risk Yönetimi, COSO, VUCA, COVID-19, Yükseköğretim 


\title{
The Importance Of Coso Corporate Risk Management In The Vuca Period: A Model Recommendation For Higher Education Institutions After The Covid-19 Epidemic \\ *
}

\begin{abstract}
Multiple management models and theories have been developed for managing institutions to create added value. These practices, which were mostly seen in private sector enterprises until the beginning of 2000s, have attracted the attention of all administrations without any discrimination and have been implemented since this date. At this point, the theories and practices of enterprise risk management (ERM) have started to take place in the programs of both private sector organizations and public administrations. Aiming to eliminate the uncertainties to the maximum, increase the sensitivity to changes and prevent possible complexity, ERM coincides with another concept, which has become increasingly important recently, on the basis of theory. This concept is VUCA. VUCA, which is spoken in all areas, especially in the business world, consists of the initials of the words volatility, uncertainty, complexity and ambiguity. Every problem that the ERM model aims to prevent comes before administrations during VUCA periods. In this sense, higher education institutions whose importance and duty are gradually increasing need a COVID-19 epidemic process as a VUCA period and then an effective and efficient ERM. Higher education institutions in our country organize ERM guides and share them with the public. However, the COVID-19 epidemic, which is on our agenda by 2020 and we do not know how long it will remain on our agenda, has made a modern, up-to-date and appropriate ERM guide necessary in higher education institutions from now on. Within the scope of the study, a model is proposed in order to enable higher education institutions to operate effective ERM processes after the epidemic.
\end{abstract}

Keywords: Enterprise Risk Management, COSO, VUCA, COVID-19, Higher Education 


\section{Giriş}

Kurumsal risk yönetimi (KRY) teori ve uygulamaları, yükseköğretim kurumlarının faaliyetlerine devam edebilmesi noktasında başvurulan temel yönetim araçlarından birisidir. Risk yönetimi algısını bütüncül bir bakışla yöneten KRY, yükseköğretim kurumlarının da uygulama alanlarına girmiş durumdadır. Özellikle belirsizliğin ve değişkenliğin arttı̆̆ VUCA dönemlerinde, KRY önleyici ve değer oluşturucu bir aktör olarak karşımıza çıkmaktadır. 2020 yılının ilk aylarından itibaren gündemimizde yer alan COVID-19 salgını da beraberinde getirdikleri dikkate alındığında tam bir VUCA dönemine işaret etmektedir.

Belirsizliklerin, değişkenliklerin arttığı ve buna bağlı olarak karmaşık süreçlerin görüldüğü salgın dönemi, yapısal önlemler ile kontrol edilebilir ve etkisi asgariye indirilebilir. Tüm bu anlatılanlar; KRY'nin temel teori ve uygulamalarının, VUCA dönemlerinde uygulanabilecek bütüncül bir bakış açısı imkânı sağladığını ve bileşenleri itibariyle bu noktada değer oluşturacak düzenlemeler yapabileceği görülmektedir. Salgın sürecinde yapısal çözümler ile sorunu önceden çözmeye yönelik aksiyonlar alan yükseköğretim kurumları, salgın sonrasında da bu kazanımları devam ettirmeli ve sistematik süreçler haline getirmelidir. Risk yönetimi özelinde birden fazla model olmasına rağmen, KRY ile ilgili teori ve uygulama genel çerçevesi, COSO'nun 2004 ve 2017 yılında yayımladığı raporlara dayanmaktadır. Gerek akademik gerek uygulama noktasında çok geniş kabullere ulaşan COSO KRY modeli, bu talebe bağlı olarak çalışmalarını güncellemektedir. Bu makale özelinde VUCA teorisi ile örtüşmesi bakımından, COSO'nun 2017 KRY modeli dikkate alınmıştır. COSO'nun 2017 yılında yayımladığı KRY (Kurumsal Risk Yönetimi-Riskin Strateji ve Performansla Uyumlaştırılması) bileşenleri şu şekilde güncellenmiş ve VUCA dönemleri için uyumlu bir yönetsel araç haline gelmiştir.

COSO'ya göre; "KRY; şirketi etkileyebilecek potansiyel olayları tanımlamak, riskleri şirketin kurumsal risk alma profiline uygun olarak yönetmek ve şirketin hedeflerine ulaşması ile ilgili olarak makul bir derecede güvence sağlamak amacı ile oluşturulmuştur. Şirketin yönetim kurulu, üst yönetimi ve tüm diğer çalışanları tarafından etkilenen ve stratejilerin belirlenmesinde kullanılan, kurumun tümünde uygulanan sistematik bir süreçtir" şeklinde tanımlanmıştır (COSO, 2004). 
VUCA kavramı, bileşenleri ve içeriği ile bir durum tespiti yapmaktadır. Kurumların içerisinde bulundukları; değişken, belirsiz, karmaşık ve muğlak şartlar bizlere bir VUCA döneminin varlığı hakkında ipuçları vermektedir. Daha çok kar amacı güden işletmeler için kullanılan bu kavram aslında, çok geniş bir etki alanına ulaşabilmektedir. Özellikle 2020 yılının başları itibariyle ortaya çıkan ve tüm dünyayı her yönüyle etkisi altına alan COVID-19 salgını, neticeleri itibariyle tam bir VUCA dönemine işaret etmektedir. Yükseköğretim kurumları da bu dönemden çok yönlü etkilenmiş ve alışılagelmiş birçok süreçlerde güncellemeler yapılmıştır. Bu güncellemelerden birisi de şüphesiz yükseköğretim kurumlarının yönetim modellerinde yaşanacaktır. Uzun yıllara sari işlemlerin çok kısa bir sürede değişmesi farklı modelleri de göz önünde bulundurma ve uygulama gerekliliğine sebep olmuştur. VUCA koşullarında yönetim modelinde gerekli düzenlemeleri belirlemek için, VUCA dönemlerinin özelliklerini ve gereklilikleri tespit etmek gerekmektedir (Popova vd.2018).

KRY'i uygulandığı kurumda, VUCA dönemlerinde daha belirgin şekilde ortaya çıkan sorunları çözmeyi amaçlamaktadır. Etkin bir risk yönetim sistemi ile artan bu belirsizlik ve muğlaklığa karşı çözüm önerileri geliştirilebilir. Bununla birlikte ilgili KRY'nin çok hızlı ve sistematik şekilde kurulması gerekmektedir. Çünkü VUCA dönemleri zaman kaybı maliyetinin en yüksek olduğu dönemlerdir. KRY'nin amacı kurumun VUCA dönemlerinden önce elde edilen kazanımların korumak ve kalıcı çözüm önerileri geliştirmektir (Kuznik, 2020). Bu nedenle, olasılıkları tanımlamak ve tanımlamak için, VUCA dönemleri tetikleyici bir rol oynayabilir. Böylece kurumlarda yıkıcı sonuçlardan ve yapısal sorunlardan makul güvence çerçevesinde korunma imkânı ortaya çıkmaktadır (Mohanta vd., 2020).

Çalışma kapsamında ilk olarak, KRY ve VUCA ilişkisi genel hatları ile açıklanmıştır. Bu sayede VUCA dönemlerinde KRY anlayışının bir kazanım oluşturacağ ifade edilmiştir. KRY teorisi, Committee of Sponsoring Organization (COSO)'nun 2017 yılında yayımladığı en güncel ve en geniş kabul alanına ulaşan KRY çerçevesi dikkate alınarak aktarılmıştır. Akabinde salgın sonrasında yükseköğretim kurumları için uygulanabilecek bir KRY model önerisi yapılmıştır. Bu model, mevcut yükseköğretim KRY rehberlerinin aksine, çok kriterli ve çok alternatifli bir derecelendirme imkânı sağlayacak- 
tır. Bu noktada Analitik Hiyerarşi Süreci (AHP)'nin temel parametrelerinden faydalanılmıştır.

\section{Araştırmanın Yöntemi ve Amacı}

Yükseköğretim kurumları gerek iç dinamikleri gerek geniş paydaş yelpazesi nedeniyle etkin ve verimli bir yönetim modeline sahip olmalıdır. Bu model; kurum hedeflerine ulaşabilme stratejilerinden, karşılaşılan/karşılaşılabilecek risklerin yönetimine kadar çok yönlü ve bütüncül bir bakış açısı sağlamalıdır. Yükseköğretim kurumlarının özellikle KRY rehberlerinin çoğu içerik ve yönteminin birbiri ile ayn olduğu gözlemlenmiştir. Çok farklı ve dinamik yapılara sahip yükseköğretim kurumlarının standart uygulamalar ile katma değer oluşturacak şekilde yönetilebilmesi mümkün değildir. Bu noktada çalışmanın temel amacı; yükseköğretim kurumlarına özellikle VUCA döneminde olduğu bu süreçte, daha esnek ve çok yönlü bir KRY haritasının oluşturulmasına ilişkin bir model önerisinde bulunmaktır. Söz konusu model önerisi, çok kriterli karar verme yöntemlerinden olan Analitik Hiyerarşi Süreci (AHP) uygulamasının araçları ile kurulmuştur. Çalışmanın diğer bir amacı AHP metodunun analiz yönteminin aktarılması değil, çok kriterli ve çok alternatifli yapısının yükseköğretim kurumlarının KRY süreçlerine sağlayacağı olumlu katkıyı vurgulamaktır. Bu kapsamda bir yükseköğretim kurumu için uygulanabilecek KRY modeli tantılacaktır.

AHP modeli; tespit edilen alternatifler içerisinde, kriterler bazından en önemli alternatiften en az önemli olana doğru bir derecelendirme yapma imkânı sunan bir modeldir. Bu noktada en temel husus, tatbik edilecek kurum için uygun alternatiflerin ve kriterlerin belirlenmesidir. Her bir alternatif grubunu, ayrı ayrı kriterler bazına değerlendirilecek matrisler oluşturulur ve kriter sayısı kadar matris hazırlanır. AHP modelinin örneklem kaygısı yoktur. Temel hedef; AHP modelinin uygulanacağ temel konu ne ise, o konu ile ilgili birinci dereceden karar vericilerin görüşlerinin alınması ve matrislere işlenmesi gerekmektedir. Konunun uzman karar vericisi sayısı kaçsa, AHP modelinin o uygulaması için örneklem sayısı da o kadardır. Dolayısıyla her bir örneklem, kriter sayısı kadar alternatif matrisi dolduracaktır. Bu matrislere AHP matrisleri denilecektir. Ardından her bir kriterin kendi içerisinde ki derecelendirilmesinin yapılacağı kriter matrisi dolduracaktır. Son olarak her bir risk grubunun gerçekleşme sıklığı ve etkisinin 
analiz edildiği risk matrisi analizi yapılacaktır. Yükseköğretim kurumlarının KRY uygulama rehberleri incelendiğinde, yalnızca risk matrisi analizi yaptıkları görülmektedir. Fakat bu model; AHP matrisi, kriter matrisi ve risk matrisi analizini bir arada yapmaktadır. İlgili analiz bütün kurum genelinde yapılabileceği gibi, birim sorumluları gözetiminde birimler bazında da yapılabilecektir. Detaylar model önerisi kısmında genişs şekilde aktarılmıştır.

\section{Yükseköğretim Kurumları için KRY Model Önerisi}

Yükseköğretim kurumları, sürekli değişen ve gelişen çevresi nedeniyle, süreçlerin işleyişinde katma değer odaklı hareket etmek zorundadır. Bu noktadan hareketle, yükseköğretim kurumlarının profesyonel yönetim anlayışları ile desteklenmesi ve güncel uygulamalar hakkında bilgi sahibi olması gerekmektedir. Bu sadece kurumların üst yönetimleri için değil, bütün olarak tüm paydaşların sorumluluk alanına girmektedir. Yükseköğretim kurumları ülkemizde kanunla belirlenmiş yükümlülükler ve sorumluluklar kapsaminda faaliyetlerine devam etmektedir. 2547 sayılı kanun, üniversitelerin iş ve eylemlerinde riayet etmesi gereken süreçleri bütün olarak ele almıştır. 2547 sayılı kanunun 1. maddesinde, kanunun amacı şu şekilde ifade edilmiştir (Yükseköğretim Kanunu, 1981);

“Bu kanunun amacı; yükseköğretimle ilgili amaç ve ilkeleri belirlemek ve bütün yükseköğretim kurumlarının ve üst kuruluşlarının teşkilatlanma, işleyiş, görev, yetki ve sorumlulukları ile eğitim - öğretim, araştırma, yayım, öğretim elemanları, öğrenciler ve diğer personel ile ilgili esasları bir bütünlük içinde düzenlemektir."

Türkiye'de özellikle kamu idarelerinin finansal ve yönetsel performanslarına ilişkin en temel kanun 5018 sayılı kanundur. (5018 Sayılı Kamu Mali Yönetimi Kontrol Kanunu, 2003). Yükseköğretim kurumları, eğitim öğretim sürecinin devamı, idari teşkilatlanmanın sağlanması vb. konuları icra ederken, çeşitli yönetimsel araçlardan faydalanmaktadır. Kurumsal yönetim ilkeleri, iç denetim uygulamaları, iç kontrol planları, KRY rehberleri bunlardan birkaçıdır. Bu denli büyük organizasyonların, faaliyetlerine etkin ve verimli şekilde devam edebilmesi amaçlanmaktadır. Bu noktada yapılan düzenlemeler (5018 sayılı Kamu Mali Yönetim Kanunu) de bu süreçlerin devamı ve denetlenmesi hususlarında rehberlik yapmaktadır. 
Yükseköğretim kurumları, beklenen değer ve kamuoyunun yakın takibi nedeniyle süreçlerinde sadece tespit edici değil, önleyici ve kontrol edebileceği yönetsel araçlara ihtiyaç duymaktadır. Kanunla belirlenen sorumluluklarla birlikte, paydaşlarca artan talep ve ihtiyaçlar, yükseköğretim kurumlarında da farklı arayışları ve gereklilikleri beraberinde getirmiştir. Bu noktada yürürlüğe giren ve yükseköğretim kurumlarını da kapsayan 5018 sayılı kamu mali yönetim ve kontrol kanunu farklı öneriler ve sorumluluklar getirmiştir.

Kanun kapsamında; iç kontrol yapısının tesisi, iç denetim birimlerinin oluşturulması, etkin ve verimli kaynak kullanımı gibi bazı düzenlemeler doğrudan belirlenmiştir. KRY gibi değer oluşturmaya yönelik bazı uygumalar ise tavsiye edilerek, kamu idarelerinin dikkatine sunulmuştur. Bu anlamda yükseköğretim kurumlarının faaliyetlerini sürdürürken etkin ve verimli olması, risk yönetimine ilişkin önleyici tedbirler alması ve kriterler çerçevesinde tercih edilirliğinin artırılması, KRY'nin faaliyetleri sonucunda doğru şekilde optimize edilebilecektir.

Yükseköğretim kurumlarının stratejik hedeflerine ulaşma noktasında önlerine çıkabilecek tüm riskleri ve risk gruplarını yönetmesi gerekliliği, KRY'ne olan ihtiyacı ortaya çıkarmıştır. Salgın kaynaklı VUCA döneminde, yükseköğretim kurumları mevcut risk yönetim modellerini revize etmeli ve yeni araçlar kullanmalıdır. Ancak bu sayede VUCA dönemi en az hasarla atlatılabilecektir. Bu süreçten kayıpsız geçebilmek mümkün değildir. Önemli olan etkin yönetim modelleri ile kaybı asgari düzeye yani yönetilebilir düzeye çekebilmektir.

$\mathrm{Bu}$ anlamda yükseköğretim kurumlarının hazırlaması gereken yeni KRY modelleri ile uzun vadeli ve kalıcı çözüm önerileri aranmalıdır. Yükseköğretim kurumları diğer kamu idarelerine oranla daha avantajlıdır. Akademik anlamda donanımlı ve yetişmiş öğretim üyesi katkısı, bu manada önemli bir zenginlik olarak düşünülmelidir. İdari kapasite ile birlikte akademik nosyonun birleşmesi, VUCA dönemlerinde yükseköğretim kurumları için etkin ve verimli bir KRY modelinin oluşturulmasına katkı sağlayacaktır. 
1. Adım - Kurumun yönetmek durumunda olduğu ana risk gruplarnnın belirlenmesi

Bu aşamada yükseköğretim kurumunun karşı karşıya kaldığı risklerin anlamlı üst başlıklar şeklinde kategorize edilmesi gerekmektedir. Kurumun 100 farklı riski olabilir ama bunların anlamlı üst başlıklara tanımlanması ve analizin bu ana risk grupları üzerinden gerçekleştirilmesi gerekmektedir. AHP modelinde alternatifler, bu modelde ana risk gruplarına karşılık gelmektedir. Çünkü derecelendirme ana risk grupları ölçeğinde gerçekleştirilecektir. Örneğin KÜRŞAD METE Yükseköğretim kurumunun tüm risklerini şu ana başlıklarda topladığını varsayalım;

- Yönetim Kaynaklı Riskler

- Mali Riskler

- Mevzuat Kaynaklı Riskler

- Stratejik Riskler

- Politik Riskler

2. Adım-Ana risk gruplarnı derecelendirirken hangi kriterlerin dikkate alınacă̆ının belirlenmesi

- İtibar/Sayginlık

- Kurumsallaşma

- Liderlik

\section{Adım-AHP ve Kriter matrislerinin oluşturulması}

Tablo 1. KÜRŞAD METE Yükseköğretim Kurumu Kriter Matrisi Örneği

\begin{tabular}{llll}
\hline & İtibar/Saygınlı & Kurumsallaşma & Liderlik \\
\hline İtibar/Saygınlık & 1 & & \\
\hline Kurumsallaşma & & 1 & 1 \\
\hline Liderlik & & \\
\hline
\end{tabular}


Tablo 2. KÜRŞAD METE Yükseköğretim Kurumu AHP Matrisi Örneği

\begin{tabular}{llllll}
\hline LiDERLiK & $\begin{array}{l}\text { Yönetim } \\
\text { Kaynaklı Riskler }\end{array}$ & $\begin{array}{l}\text { Mali } \\
\text { Riskler }\end{array}$ & $\begin{array}{l}\text { Mevzuat } \\
\text { Kaynaklı Riskler }\end{array}$ & Stratejik Riskler & Politik Riskler \\
\hline $\begin{array}{l}\text { Yönetim Kaynakl } \\
\text { Riskler }\end{array}$ & 1 & & & & \\
\hline Mali Riskler & & 1 & & & \\
\hline $\begin{array}{l}\text { Mevzuat } \\
\text { Kaynaklı Riskler }\end{array}$ & & 1 & & \\
\hline Stratejik Riskler & & & & 1 & \\
\hline Politik Riskler & & & & & \\
\hline
\end{tabular}

4. Adım - Örnekleme dâhil edilen karar vericilerin ve uzmanların matrisi doldurması

AHP modeli 1-9 arasında yer alan değerlere atanmış her bir ifade ile doldurulur. Bu değerler içerişimde 1-3-5-7-9 değerleri ana değerleri, 2-4-6-8 değerleri ise ara değerleri ifade etmektedir.

\section{Adım - Tutarlılık testleri uygulaması}

12 farklı aşamadan oluşan adımlar tek tek uygulanır ve her bir matris için tutarlılık testleri yapılır. Sadece tutarlı olan matrisler analize dâhil edilir. AHP modelinin tutarlılığının (gerek alternatifler gerekse de kriterler açısından) test edildiği temel aşamalar şu şekilde gerçekleşmiştir (Karakaya, 2019);

1. Çalışma için alternatiflerin (risklerin) ve kriterlerin tespit edilmesi,

2. Alternatifleri ve kriterleri matrislere anlamlı şekilde yerleştirme,

3. Yargisal örneklem yoluyla belirlenen kişilerden ilgili alternatifleri ve kriterleri dikkate alacak şekilde verileri toplamak,

4. Her bir matris için simetrik matris değerlerinin elde edilmesi (Köşe matrisinin altında ki değerlerin bulunması, 1 / Veri)

5. Tüm alternatiflerin her bir kriter bazında normalizasyon değerlerinin bulunmas1,

6. Normalizasyon matrisinde ki her satırın geometrik ortalaması alınarak, göreli ağırlık matrisinin bulunması, (Matris tutarlı çıarsa, analiz bu değer üzerinden yapılacaktır.) 
7. Verilerin işlendiği temel matris ile göreli ağırlık matrisinin çarpımı sonucunda tutarlılık matrisinin oluşturulması,

8. Tutarlılık matrisi ile göreli ağırlık matrisi bölünerek ham oran sütunu hesaplanir,

9. Ham oran sütununun aritmetik ortalaması alınarak $\lambda$ max. değeri bulunur,

10. $(\lambda$ max. $-n) /(n-1)$ formülü ile tutarlllık göstergesi (CI) hesaplanır,

11. Matris boyutlarına göre sabitlenmiş, Rassal Tutarlılık (RI) indeksi belirlenir,

12. $\mathrm{CI} / \mathrm{RI}$ formülü uygulanarak, Tutarlılık Oranı (CR) hesaplanır.

\section{Adım - Tutarlı matrislerin dâhil edildiği örnek analiz sonuçlan}

Tutarl her bir AHP matrisi, kriter matrisi ve risk matrisinin analizi sonucunda, yükseköğretim kurumu için bir risk haritası elde edilecektir. Bu sayede ana alternatifler yani ana riskler için karar vericilerin ve uzmanların her bir kriter bazında atfettikleri önem düzeyleri belirlenmiş olacaktır. Bu da yekûn olarak, KÜRŞAD METE yükseköğretim kurumunun KRY yol haritasını çıkaracak ve temel hedeflere ulaşma noktasında ortaya çıkabilecek risklere ilişkin önem düzeylerini belirleyecektir.

Tablo 3. KÜRŞAD METE Yükseköğretim Kurumu AHP Skorlarn Özet Tablosu

\begin{tabular}{llll}
\hline & İtibar/Sayginlık & Kurumsallaşma & Ulusal/Uluslararası Liderlik \\
\hline Yönetim Kaynaklı Riskler & 0,11 & 0,11 & 0,09 \\
\hline Mali Riskler & 0,08 & 0,03 & 0,11 \\
\hline Mevzuat Kaynaklı Riskler & 0,12 & 0,12 & 0,07 \\
\hline Stratejik Riskler & 0,18 & 0,14 & 0,21 \\
\hline Politik Riskler & 0,15 & 0,11 & 0,20 \\
\hline
\end{tabular}

Tablo 4. KÜRŞAD METE Yükseköğretim Kurumu Risk Matrisi

\begin{tabular}{lllllll}
\hline Riskler & $\mathbf{K}_{\mathbf{1}}$ & $\mathbf{K}_{\mathbf{2}}$ & $\ldots$. & $\mathbf{K}_{\mathbf{n}}$ & $\begin{array}{l}\text { Geo. } \\
\text { Ort. }\end{array}$ & $\begin{array}{l}\text { Yüzde } \\
\text { Dağıllım }\end{array}$ \\
\hline Yönetim Kaynaklı Riskler & 9 & 12 & $\ldots$. & 12 & $\mathbf{1 2 , 4 0}$ & $\mathbf{0 , 1 5}$ \\
\hline Mali Riskler & 20 & 15 & $\ldots$. & 9 & $\mathbf{1 0 , 0 1}$ & $\mathbf{0 , 1 2}$ \\
\hline Mevzuat Kaynaklı Riskler & 9 & 6 & $\ldots$. & 16 & $\mathbf{9 , 2 5}$ & $\mathbf{0 , 0 9}$ \\
\hline Stratejik Riskler & 12 & 5 & $\ldots$. & 16 & $\mathbf{1 4 , 4 2}$ & $\mathbf{0 , 1 1}$ \\
\hline Politik Riskler & 9 & 4 & $\ldots$. & 12 & $\mathbf{9 , 5 6}$ & $\mathbf{0 , 1 0}$ \\
\hline
\end{tabular}




\section{Adım - Nihai KRY Derecelendirmesi}

KÜRŞAD METE yükseköğretim kurumu bünyesinde; risk yönetimine ilişkin uzmanların ve karar vericilerin doldurduğu AHP, kriter ve risk matrislerinden tutarlı olanlar, sonuç tablosunda gösterilir. Sonuç tablosunda aktarılmak istenen, KÜRŞAD METE yükseköğretim kurumunun KRY teori ve uygulaması çerçevesinde oluşturulan ve yönetilen risk gruplarının kriterler bazında nihai önem derecesidir. Salgın, ekonomik/siyasi depremler vb. VUCA dönemlerinde, kurumun yürütmesi ve gerekirse revize etmesi gereken risk haritaları, çok kriterli ve çok alternatifli bir model ile işlenmiştir. Diğer taslak bulgularda aktarıldığı gibi, KÜRŞAD METE yükseköğretim kurumunun nihai KRY önem derecesi şu şekilde oluşacaktır;

\section{Tablo 5. KÜRŞAD METE Yükseköğretim Kurumu KRY Tablosu}

ÖZET

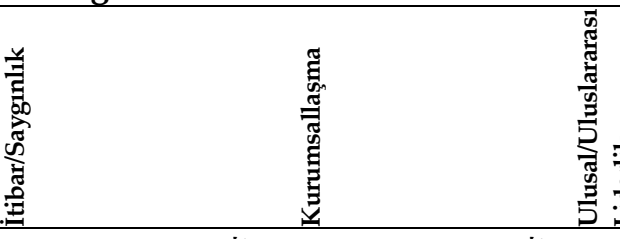

\begin{tabular}{|c|c|c|c|c|c|c|c|c|c|c|c|c|}
\hline & & & 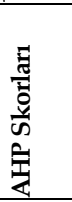 & 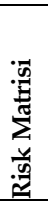 & & 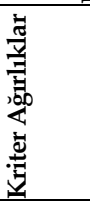 & 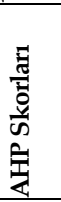 & $\sum_{0}$ & & 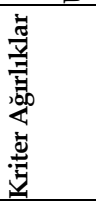 & 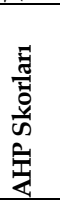 & 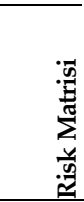 \\
\hline Yönetsel Riskler & 0,12 & 0,11 & 0 , & & 0,13 & 0,11 & & 0,15 & 0,14 & 0,09 & & 0,15 \\
\hline Finansal/Ekonomik Riskler & 0,12 & 0,08 & 0 & & 0,13 & 0,03 & & 0,12 & 0,14 & 0,11 & & 0,12 \\
\hline Mevzuat Kaynaklı Riskler & 0,12 & 0,12 & $0,($ & & 0,13 & 0,12 & & 0,09 & 0,14 & 0,07 & & 0,09 \\
\hline Çevresel Riskler & 0,12 & 0,18 & 0 , & & 0,13 & 0,14 & & 0,11 & 0,14 & 0,21 & & 0,11 \\
\hline Politik Riskler & 0,12 & 0,15 & 0, & & 0,13 & 0,11 & & 0,10 & 0,14 & 0,20 & & 0,10 \\
\hline
\end{tabular}

\section{Tartışma, Sonuç ve Öneriler}

Yükseköğretim kurumları, organizasyonlarının büyüklüğü ve çok geniş kesimleri etkileyen alanı nedeniyle, etkin ve verimli yönetilmesi gereken idarelerdir. Eğitim-öğretim hayatının rutin hiyerarşisinin son halkası olması nedeniyle, muhatapların en çok talepkar olduğu eğitim birimleridir. $\mathrm{Bu}$ noktada klasik kamu idarelerinin aksine, akıla ve önleyici uygulamalar 
kullanmak durumundadır. Toplumun tümünü etkileyen ve yıkıcı sonuçlar doğurabilen VUCA dönemlerinde bu ihtiyaç kat kat artmaktadır.

KRY teori ve uygulamaları, kurumsal bir yönetim arzusunun olduğu her alanda uygulanması gereken bir yönetsel araçtır. Bu anlamda özel ya da kamu idareleri farkı gözetmemektedir. Uygulandığı her kurumda katma değer oluşturamaya yönelik uygulama ve araçlara sahiptir. Risk yönetimi olgusuna yönelik geliştirilen ve son çeyrek yüzyılda tüm idareleri ilgilendiren bu anlayış, KRY'nin ortaya çıkışının temel sebepleri arasında yer almaktadır. Yükseköğretim kurumlarının yayımladığı KRY'i raporları incelendiğinde söz konusu yöntem ve metotların katma değer oluşturmaktan uzak olduğu görülmektedir. Yalnızca gerçekleşme sıklığı ve etkisi kapsamında yapılan KRY uygulamaları akılcı ve yapısal sonuçlar veremeyecektir. Bu anlamda yükseköğretim kurumları için, çok kriterli ve çok alternatifli bir KRY hiyerarşisinin oluşturulması gerekmektedir. Bunun temel bir ihtiyaç olduğu ve desteklenmesi gerekliliği istisnasız tüm birimler tarafından anlaşılması ve süreçlere destek olunmalıdır.

KRY teorisi, kapsam ve içerik bakımından iç denetim, kurumsal yönetim ve iç kontrol başta olmak üzere birçok yönetsel anlayış ile ilişki halindedir. Bahsi geçen diğer anlayışlar gibi; KRY de uygulandığı alanlarda değer oluşturmayı hedeflemektedir.

KRY, kurumların risklerinin yönetimi yoluyla katma değer üretmektedir. Bu yönüyle kurumların denetim süreçlerine de olumlu katkılar sunmaktadır. KRY, makul güvence sunma noktasında önemli bir referans uygulama olarak karşımıza çıkmaktadır. KRY, denetim birimlerinin kontrol ve gözetimi altında faaliyetlerini sürdürmektedir. Kurumun tüm iş/işlemlerinde birim, bölüm tasnifi olmaksızın; kurumun bütünü ilgi alanına alınır ve temel aksiyonların tamamı tüm kurum için uygulanır. Bu manada klasik risk yönetim uygulamalarından farklılık göstermektedir.

Kurum özelinde belirlenen hedeflere ulaşma noktasında, kurum stratejilerinin tespiti, uygulanması ve gerekirse revize edilmesi süreçleri KRY'nin temel çıktıları arasındadır. KRY uygulamaları netice olarak bir değer oluşturma, mevcut değeri artırma ve koruma motivasyonu ile hareket etmektedir. Bu nedenle tüm paydaşların bu bilinçte olması ve gerekli organizasyonların bu çerçeve de uygulanması gerekmektedir. 
KRY'i uygulandığı kurumda, VUCA dönemlerinde daha belirgin şekilde ortaya çıkan sorunları çözmeyi amaçlamaktadır. Etkin bir risk yönetim sistemi ile artan bu belirsizlik ve muğlaklığa karşı çözüm önerileri geliştirilebilir. Bununla birlikte ilgili KRY'nin çok hızlı ve sistematik şekilde kurulması gerekmektedir. Çünkü VUCA dönemleri zaman kaybı maliyetinin en yüksek olduğu dönemlerdir. KRY'nin amacı kurumun VUCA dönemlerinden önce elde edilen kazanımların korumak ve kalıcı çözüm önerileri geliştirmektir (Kuznik, 2020). Bu nedenle, olasılıkları tanımlamak ve tanımlamak için, VUCA dönemleri tetikleyici bir rol oynayabilir. Böylece kurumlarda yıkıcı sonuçlardan ve yapısal sorunlardan makul güvence çerçevesinde korunma imkânı ortaya çıkmaktadır (Mohanta vd., 2020).

VUCA dönemlerinde tüm sistemlerin yapısal sorunlarla karşılaşması kaçınılmazdır. Fakat bu duruma uygun geliştirilecek aksiyonlar ve yeni yönelimler, kurumların gelecek inşalarında kullanılacak temel kazanımlardan olacaktır. Her yönüyle negatif çağrışımlarda bulunan VUCA dönemleri, ancak rasyonel, kabiliyetli ve proaktif yönetim hamleleri ile kontrol edilebilir. Bu noktada kurumların kullandığı en temel araçlardan olan KRY, VUCA dönemleri için teori ve uygulama noktasında önemli tedbirler ve önemli firsatlar sunmaktadır.

KRY'nin hem kendi içerisinde hem de ilişkili bulunduğu yönetsel araçlar ile olan azami uyum ve bütünlüğü, VUCA dönemlerinde kurumlar için önemli avantajlar sağlayabilecektir. Etkin ve verimli bir iç denetim sistemi, bireysel kapasiteye bağlı olmaktan kurtulmayı mümkün kılan kurumsal yönetim ve iç kontrol gibi temel yönetim modelleri, KRY ile yakın ve bazı noktada ortak literatüre sahiptir. VUCA döneminde yönetim, bir veya birkaç yönetim sistemi veya aracının ayrı ayrı veya birlikte kullanıldığı bir yönetim anlayışı olmayacaktır.

Artık, tüm sistemleri birlikte çalıştıracak çerçeveler (framework) ve yönetim modelleri geliştirilmesi, bunun da yerel kültür gözetilerek yapılması gerekmektedir (VUCA Döneminde Yönetim, 2016).

VUCA dönemleri temelde, kurumların uzun dönem amaçlarını temsil eden vizyonlarına yönelik bir tehdit olarak karşımıza çıkmaktadır. Bu noktadan hareketle mevcut ya da önerilen KRY modellerinin, kurumların vizyonları ile uyumlu ve koruyucu olması gerekmektedir. Bu noktada stratejik opsiyonlar sunmalı ve risk yönetimini bu çerçevede sürdürerek kurumların vizyonlarını muhafaza etmelidir. KRY 2017 modelinde aktarılan ana bile- 
şenlerden strateji ve hedef belirleme aşaması ne kadar sağlam dizayn edilebilirse, bu tehdit de o kadar kısa sürede yönetilebilir olabilir.

Yine VUCA dönemlerinin karakteristiği olan belirsizlik durumlarını, anlamlı hale getiren ve bu noktada rasyonel risk yönetimi hamleleri sunan bir KRY'nin varlığı elzemdir. Bu sayede kurumların olası tüm belirsizliklere karşı geliştirebileceği aksiyonlar oluşturulabilir ve risklere yönelik katma değer oluşturacak tedbirler alınabilir. KRY'nin birinci derece sorumluları olan üst yönetimler her aşamada olduğu gibi bu aşamada da sürecin tam merkezinde yer almaktadırlar. Bu noktada KRY 2017 modelinde detaylandırılan yönetişim ve kültür bileşeni ne kadar doğru dizayn edilebilir ve üst yönetimce korunur ve uygulanabilirse o kadar katma değer oluşturulabilecektir. VUCA dönemlerinde kaos çağrışımı yapan karmaşıklık aşaması, yine KRY'nin temelde önerdiği önlemler sayesinde daha net ve berrak süreçler haline getirilebilir.

Yükseköğretim kurumları için uygulanabilirliği mümkün olan KRY taslağı, idareye farklı kazanımlar elde etme imkânı sunabilecektir. Bu farklılıklar aşağıdaki maddeler çerçevesinde özetlenebilir;

I. Yükseköğretim kurumları için sadece gerçekleşme sıklı̆̆ ve şiddeti temelinde yürütülen bir risk yönetimi, katma değer oluşturmaktan uzaktır. Bu nedenle AHP temelli, çok kriterli ve çok alternatifli bir KRY derecelendirme yapısının oluşturulması gerekmektedir.

II. Yükseköğretim kurumlarının yürüttüğü bu denli büyük organizasyonlar, riskleri ile ilgili bilgi sahibi olmalı ve bunların yönetimi ile ilgili nicel verilere sahip olmalıdır. Önerilen KRY modeli, tam olarak bunu amaçlamaktadır.

III. Tanımlanan risk gruplarına karşı oluşturulacak aksiyonlar ile, önleyici ve kontrol edici bir KRY süreci tesis edilebilecektir.

IV. Söz konusu KRY modeli, üst yönetimler tarafından her aşamada desteklenmelidir, bu sayede kazanımın elde edileceği inanc1, kurumun tüm birimlerine sirayet edebilecektir.

V. Yeni KRY modeli, kurumun tüm birimlerine eğitimler ile tanttlarak, bütüncül bir KRY yönetimi aracllı̆̆yyla katma değer oluşturacak süreçlerin inşa edilebilmesi mümkün olacaktır. 
VI. Risk ve departman ayrımı göstermeden tesis edilecek KRY sayesinde, her bir risk potansiyeli için bütüncül yaklaşımlar tanımlanacaktır. Bu sayede risk yönetimi ile ilgili kronikleşme sorunu ortada kalkacaktır.

VII. KRY; mevcut modeli her ihtiyaç durumunda revize ederek, çok kısa sürelerde çok net sonuçlara ulaşabilme imkânı sağlamaktadır.

VIII. VUCA dönemlerinde yıkıcı olabilen ve yükseköğretim kurumlarını da birinci dereceden etkileyen olumsuz dişsallıklar, etkin ve verimli bir KRY modeli ile asgari etki alanına çekilebilir.

IX. Özellikle VUCA dönemlerinde görülen büyüme ve kapasite artıramama sorunu, etkin bir KRY modelinin tesisi ile asgari seviyelere çekilebilir ve yapısal büyüme devamlılığı sağlanabilir.

X. Küreselleşme etkisinin giderek arttığı ve lehte/aleyhte oluşabilecek tüm aksiyonların çok kısa sürelerde dünyanın herhangi bir yerine ulaşabilme riski, önerilen KRY modeli ile asgari seviyelere indirilebilir.

XI. İlgili KRY modeline intibak edebilmesi için, ilgili personellerin ve idarecilerin teori ve uygulamaya dönük risk yönetimi donanımlarını sağlaması gerekmektedir.

XII. Yükseköğretim kurumları için önerilen KRY modeli ile standart risk yönetimi prosedürleri oluşturulabilir ve değer oluşturabilme kabiliyeti test edilebilir.

XIII. Etkin ve verimli KRY modeli ile yasal ve mevzuat kaynaklı yükümlülükler daha sıkı takip edilebilir ve uygun raporlama imkânları elde edilebilir. 


\title{
EXTENDED ABSTRACT
}

\section{The Importance Of Coso Corporate Risk Management In The Vuca Period: A Model Recommendation For Higher Education Institutions After The Covid-19 Epidemic}

\author{
Gencay Karakaya \\ Istanbul Commerce University
}

Enterprise Risk Management (ERM) aims to manage the current or possible risks in the activities of organizations with a holistic view. In this respect, it has the role of confirming and preventing in the processes of creating added value of the organization. ERM creates added value by managing the risks of the organizations. With this aspect, it also contributes positively to the audit processes of the organizations. ERM is an important reference practice about presenting reasonable assurance. ERM carries on its activities under the control and supervision of audit units.

The concept of VUCA determines the situation with its components and content. The volatile, uncertain, complex and ambiguous conditions that the organizations have been experiencing give us a clue about the existence of a VUCA period. This concept, which is mostly used for profit-oriented organizations, would actually reach a sweeping impact area. It is inevitable that all systems encounter structural problems in VUCA periods. However, the actions and new orientations to be developed according to this situation will be among the main acquisitions that will be used for the organizations' building a future. VUCA periods, which creates negative connotation in every aspect, can only be controlled by rational, intelligent and proactive management moves. ERM, which is one of the most basic means to be used by organizations at this point, provides significant precautions and opportunities in relation to theory and practice for VUCA periods.

In the study, the relation of ERM and VUCA is explained in general terms. By this means, it is expressed that ERM notion creates an acquisition in VUCA periods. Afterward, an ERM model is proposed to be able to be applied for higher education institutions after the pandemic. This model 
will provide a multi criteria and multi alternative rating opportunity in contrast to the present ERM guides of higher education. At this point, basic parameters of Analytic Hierarchy Process (AHP) are utilized.

ERM theory is cited by taking into consideration the framework of ERM, which is the latest and has the widest acceptance as being published by Committee of Sponsoring Organization (COSO) in 2017.

The components of ERM (Enterprise Risk Management- Integrating with Strategy and Performance), which was published by COSO in 2017, are updated in this way and they have been managerial tools that are compatible for VUCA periods. The renewed COSO ERM framework gives the users the opportunity to establish a more detailed and holistic structure of ERM with five main components and twenty subcomponents. Here are the five main components (COSO, 2017);

- Governance and Culture

- Strategy and Objective-Setting

- Performance

- Review and Revision

- Information, Communication and Reporting

An effective risk management system would help to develop solution proposals against the increasing uncertainty and ambiguity. In addition to this, the relevant ERM is supposed to be established very quickly and systematically. Since, VUCA periods are the periods in which the cost of loss of time is highest.

Higher education institutions make use of various managerial tools while conducting their duties such as the continuation of education and training process and ensuring administrative organization etc. Corporate governance principles, internal audit practices, internal control plans and ERM guides are some of these tools. It is aimed that such big organizations are able to carry out their activities effectively and productively.

Along with the responsibilities determined by laws, increased demands and needs by stakeholders bring about different quests and necessities in higher education institutions, as well. The public finance management and control law no.5018, which entered in force about this context and also involves higher education institutions, has brought different proposals and responsibilities. 
Within the scope of law, there are some directly determined regulations such as the establishment of internal control structure, foundation of internal audit units, effective and productive use of resource. Some valuecreation oriented practices like ERM are recommended and presented to the attention of public administrations.

In this regard, there must be a search for long term and permanent solution proposals with new ERM models that are supposed to be prepared by higher education institutions. Higher education institutions have an advantage over other public administrations. The contribution of academically equipped and qualified faculty members should be considered as a significant wealth in this sense.

The main target of this study is to propose a model, which is related with creating a more flexible and multi-directional ERM map, for higher education institutions especially in this process that they have been experiencing VUCA period. The aforementioned model proposal is established by the tools of Analytic Hierarchy Process (AHP) practice, which is one of the multi criteria decision making methods. Another target of the study is not to transfer the method of analysis of AHP method; but to emphasize the positive contribution of multi criteria and multi alternative structure of AHP method on the ERM processes of higher education institutions. In this context, there will be introduced an ERM model that can be applied for a higher education institution.

The AHP model preferred in the study is a model that enables to rank the alternatives from the most important to the least important on the basis of criteria among the determined alternatives. At this point, the key issue is the determination of suitable alternatives and criteria for the organization to which the model will be applied. Matrices, which could evaluate each group of alternatives on the basis of different criteria, are created. And they are created as much as the number of criteria. AHP model does not have sample anxiety.

This model carries out the analysis of AHP matrix, criteria matrix and risk matrix all together. As the relevant analysis can be made throughout the whole organization, it can also be carried out on unit basis under the control of the unit supervisors. The details have been explicitly given in 'model proposal' part. When the ERM reports, which are published by higher education institutions, are examined, it is seen that the present techniques and 
methods are not able to create added value. The ERM practices do not produce reasonable and structural results in case that they are only applied within the context of realization frequency and effect. In this regard, it is required to create a multi criteria and multi alternative ERM hierarchy for higher education institutions. It should be recognized by all units without any exception that this is a basic need and ought to be supported; and they should lend assistance to the processes.

\section{Kaynakça / References}

COSO. (2004). Enterprise risk management- integrated framework, application techniques. 12.03.2020 tarihinde , $\quad$ https://www.coso.org/Pages/ermintegratedframework.aspx adresinden erişilmiştir.

COSO, (2017). Enterprise risk management integrating with strategy and performance: Executive summary. 12.03.2020 tarihinde https://www.coso.org/Pages/ermintegratedframework.aspx adresinden erişilmiştir.

Karakaya, G. (2019). COSO kurumsal risk yönetimi-riskin strateji ve performansla uyumlaştrılmasına ilişkin düzenleme çerçevesinde getirilen güncellemeler. Denetişim, 18, 15-22.

Kaya, B. (2016). VUCA döneminde yönetim. 14.05 .2020 tarihinde http://bertankaya.net/2016/10/vuca-doneminde-yonetim/ http://bertankaya.net/2016/10/vuca-doneminde-yonetim/ adreslerinden erişilmiş̧tir.

Kuznik T. (2016). Risk management in a vuca world: practical guidelines based on the example of a multinational retail group. Mack O., Khare A., Krämer A., Burgartz T. (eds) Managing in a VUCA World içinde Springer, Cham

Mohanta B., Nanda P. ve Patnaik S. (2020). Management of V.U.C.A. (Volatility, Uncertainty, Complexity and Ambiguity) Using Machine Learning Techniques in Industry 4.0 Paradigm. Patnaik S. (eds) New Paradigm of Industry 4.0. Studies in Big Data içinde Springer, Cham

Pierce, E. M., ve Goldstein, J. (2018). ERM and strategic planning: A change in paradigm. International Journal of Disclosure and Governance, 15(1), 51-59.

Popova, N., Shynkarenko, V., Kryvoruchko, O., \& Zéman, Z. (2018). Enterprise management in VUCA conditions. Economic annals-XXI, (170), 27-31.

Saaty, T. (1980). The analytic hierarchy process. Mc Graw - Hill, New York,

Satty, T. L. (2004). Decision making: The analytic hierarchy and network processes (AHP/ANP). Journal Of Systems Science and Systems Engineering, 13(1), 1-35. 
Yükseköğretim Kanunu. (1981). Yükseköğretim Kanunu. 11.04 .2020 tarihinde, https://www.mevzuat.gov.tr/MevzuatMetin/1.5.2547.pdf adresinden erişilmiştir.

5018 Sayılı Kamu Mali Yönetimi Kontrol Kanunu. (2003). Resmi Gazete. Sayı:25326 12.05.2020, https://www.mevzuat.gov.tr/MevzuatMetin/1.5.5018.pdf adresinden alınmıştır

\section{Kaynakça Bilgisi / Citation Information}

Karakaya, G. (2020). Vuca dönemlerinde Coso kurumsal risk yönetiminin önemi: Covid-19 salgın sonrası yükseköğretim kurumları için model önerisi. OPUS-Uluslararası Toplum Araştırmaları Dergisi, 16(30), 2863-2882. DOI: 10.26466/opus.791495 